https://helda.helsinki.fi

\title{
Prevalence and disease association of human parvovirus B19 in Iran : a systematic review
}

\section{Sabahi, Mohammadmahdi}

2019-08

Sabahi , M , Salehipour , A , Kazemi , A , Sadeghi , M , Decaro , N , Mozhgani , S-H , Jalilian , F A \& Yaghoobi , M H 2019 , ' Prevalence and disease association of human parvovirus B19 in Iran : a systematic review ' , Future Virology , vol. 14 , no. 8 , pp. 561-570 . https://doi.org/10.2217/fvl-2019-00

http://hdl.handle.net/10138/318567

https://doi.org/10.2217/fvl-2019-0046

acceptedVersion

Downloaded from Helda, University of Helsinki institutional repository.

This is an electronic reprint of the original article.

This reprint may differ from the original in pagination and typographic detail.

Please cite the original version. 


\title{
The prevalence of parvovirus B19 at different aspects of its disease in Iran: a systematic review
}

\author{
Mohammadmahdi Sabahi ${ }^{\dagger}$, Arash Salehipour $^{\dagger}$, Azin Kazemi $^{{ }^{\dagger}}$, \\ Mohammadreza Sadeghi², Mojtaba Hedayat Yaghoobi $^{3}$, Nicola Decaro ${ }^{4}$, \\ Farid Azizi Jalilian ${ }^{5 *}$
}

1. Student Research Committee, Hamadan University of Medical Sciences, Hamadan, Iran.

2. Department of Virology, University of Helsinki, Helsinki, Finland.

3. Department of Infectious Disease, School of Medicine, Alborz University of Medical Sciences, Karaj, Iran.

4. Department of Veterinary Medicine, University of Bari, Bari, Italy

5. Department of virology, Faculty of medicine, Hamadan University of Medical Sciences, Hamadan, Iran.

$\dagger$ These authors contributed equally to this work.

*Author to whom correspondence should be addressed; Department of Virology,Faculty of medicine, Hamadan University of Medical Sciences, Shahid Fahmide St, Hamadan, Iran.

E-Mail: azizifarid@gmail.com; f.jalilian@umsha.ac.ir

Parvovirus B19 is a single-stranded DNA virus that has been linked to many clinical diseases and syndromes including respiratory, neurological, hematological, congenital, etc. However, its role in the some of diseases not completely understood. During the last 10 years a huge number of reports on B19Vassociated diseases and epidemiological information of the incidence of B19V have been documented. The aim of this review is to describe the current state of knowledge of the prevalence and association with different manifestations of B19V diseases. Evaluation and diagnosis of $\mathrm{B} 19 \mathrm{~V}$ infections should rely on investigation of anti-B19V IgG, IgM antibodies and detection of B19V DNA in serum or CSF.

The results of this study show a relatively high prevalence of $\mathrm{B} 19 \mathrm{~V}$ diseases in all age groups of the Iranian population.

\section{Introduction:}

Virus

The family Parvoviridae contains two subfamilies Parvovirinae and Densovirinae. The latter subfamily infects arthropods. Within the Parvovirinae there are five genera which include viruses of humans, Erythrovirus, Dependovirus, Bocavirus, Tetraparvovirus and Protoparvovirus. Parvoviruses in general are among the smallest viruses known, with size between 21 and $25 \mathrm{~nm}$ in diameters and They are icosahedral. These viruses are highly stable in adverse condition, resisting a wide range of $\mathrm{pH}$ from $\mathrm{pH} 3$ to 9 and $60^{\circ} \mathrm{C}$ for few hours and also disinfectants. They do not contain envelope (1-3). The ssDNA parvovirus genome is of negative polarity

The genus Erythrovirus contains the important human pathogen parvovirus B19. B19V encapsidates 50\% of plus and minus strands in its virions.

In 2002, new sequence analysis of human erythroviruses revealed organization into three genotypes (1).

Genotype1 and two mostly found in the western countries and genotype $3(\mathrm{~B} 19 \mathrm{~V})$, in sub-Saharan and south America, however Genotype 3 is spreading around the world, and already has spread in the MiddleEast and Iran (2).

\section{Transmission, Infection and diseases}

Since the discovery of B19V in the 1975 , research has progressed rapidly to identify its association with new diseases. Human parvovirus B19 (B19V) has been linked with a wide range of diseases and clinical syndromes, including erythema infectiosum (fifth disease), transient aplastic crisis, persistent infection manifesting as pure red cell aplasia in immunocompromised individuals, nonimmune hydrops fetalis, arthritis (especially in young women). Clinical manifestations of $\mathrm{B} 19 \mathrm{~V}$ infection are based on immunological and hematological status of the patient (4).

The commonest, fifth disease, is a mild self-limited disease seen in normal children and adults. Fever and 
rash as common manifestations of $\mathrm{B} 19 \mathrm{~V}$ infection are time and again mistaken with measles or rubella.

$\mathrm{B} 19 \mathrm{~V}$ is a human pathogen that has different ways of transmission. B19V transmitted to susceptible individuals via respiratory secretions (5). respiratory transmission between acutely infected individuals is also happening (6).

B19V infection has been shown to be transmissible by blood and blood products and from clotting factor products that result in transient aplastic crisis. Transmission through transfusion of infected blood donated by apparently healthy and asymptomatic blood donors is also occurs (7-9).

Virus has potential for trans placental transmission in susceptible mothers. Rate of vertical transmission in maternal infection is $33-51 \%$ of cases, and the rate of adverse fetal effect is around $10 \%(10,11)$.

Congenital infection has been associated with severe fetal anemia, myocarditis, fetal hydrops, and death (10).

After virus enter blood by direct, respiratory or other ways, can spread and then can lead to viremia. The virus could replicate in erythroid progenitor cells and thus inhibits erythropoiesis, it can cause transient aplastic crisis (TAC). The cellular receptor necessary for B19V infectivity is globoside. Other non-erythroid cells can express this receptor, including megakaryocytes, endothelial cells, cardiac myocytes and placental trophoblast cells. In adults, myocarditis was rarely reported $(5,12)$.

The rarer but more critical situation of infection occur only in patients with pregnancy a requirement for accelerated erythropoiesis, e.g., in chronic hemolytic anemia, an underlying congenital or acquired immunodeficiency.

In immunocompromised patients, the continued lysis of RBC precursors can cause a severe, chronic pure red cell aplasia and anemia and, less frequently, thrombocytopenia, pancytopenia, and neutropenia.

Though the host immune response can keep the B19V infection in check, the virus may still be found in some regions of the body like the bone marrow $(13,14)$.

\section{Diagnosis, Vaccination and Treatment}

diagnosis of $\mathrm{B} 19 \mathrm{~V}$ infection is based on both serological and molecular methods. IgM detection is used to diagnose in the presence of B19V. Antibodies are synthesized approximately 1-2 weeks after viremia. IgG appears shortly after $\operatorname{IgM}$ and persists lifelong with slowly decrease in titer. Molecular testing aimed to the confirmation of suspected active infections before anti bodies increase. Quantitative B19V DNA level might also be useful in management and follow up of disease. There are no known effective antiviral drugs and vaccine for the treatment and also prevention of $\mathrm{B} 19 \mathrm{~V}$ infections. Since Blood transfusion is an important part of day-to-day clinical practice therefore Monitoring blood and blood products a potential source of virus, specially for use in patients with immunodeficiency, is necessary.

\section{Epidemiology}

$\mathrm{B} 19 \mathrm{~V}$ infection is more prevalent in the spring and major epidemic outbreaks occur every four years (15).

\section{purpose}

The objectives of this systematic review are to search for cases of B19V-related disease and clinical syndromes and identify the prevalence of B19V among different ages and regions in Iran and also effect on certain conditions among different populations.

\section{Materials and methods}

Following the preferred items for reviews, we performed an internet-based search using pubmed and Scopus data bases. As there are no previous review articles concerning the general status of B19V among the Iranian population in this study we have gathered data by searching the keywords "parvovirus B19" and Iran" using the pubmed and scupus databases. The number of articles found using the two keywords was 29 , hence the general keywords. Of the 29 articles 26 were chosen which contained data about the seroprevalence of $\mathrm{B} 19 \mathrm{~V}$ among different populations with special conditions in Iran. The articles are put into 11 groups as follows: HIV positive patients, Women with history of abortion/miscarriage, Kidney transplant patients, Thallasemic patients, Patients suffering from hereditary spherocytosis, Patients suffering from Bone marrow suppression, Patients suffering from Behcet's disease, Renal transplant patients, pre-school age/young adult individuals, hemophilia patients, and children with measles- and rubella-like illness.

The search was performed combining the terms 'human parvovirus B19' and 'Iran' without language and time restrictions. In addition, all cited references listed in the identified papers were hand-searched for other relevant articles. An article was considered for inclusion in the systematic review if it reported cases with B19V infection that presented with any clinical syndrome. A case was considered eligible for the following reasons: (i) if data of age, sex, description of manifestations and investigation were presented and (ii) if B19V infection was diagnosed in the presence of B19V DNA(iii) if $\mathrm{B} 19 \mathrm{~V}$ infection was diagnosed in the presence of anti B19V IgM or IgG specific antibodies in the serum or the CSF.

The computerized search was conducted for the last time on 2018. The preferred reporting items for systematic review and meta-analysis guidelines were followed.

Data were summarized using percentages and cross tabulations. Comparisons between subgroups were made using Fisher's exact tests. The 95\% confidence intervals (CIs) for percentages were calculated using the Wilson method. All statistical analyses used the conventional two-sided 5\% significance level and were carried out using SPSS version 20 and CIA version 2.0.EI. 


\section{Parvovirus B19 in the general population}

A total of two studies have been conducted that concern the general population in Iran, who did have no disease, disorder or abnormal condition. In the study conducted by Ziyaeianin Shiraz, 908 individuals aging 5-25 years, were studied for the anti-B19V IgG. The patients were put into 7 age categories. Also this study was the only research on pre-school age/young adults. In the other study 1500 blood samples from Tehran were studied by Salimi for the anti-B19V IgG.

\section{pre-school age/young adults}

In this group only one study was conducted by Ziyaeyan et al in 2007. 908 individuals (505 females and 403 male) from 5-25 years old were assessed in Shiraz Iran.

The patients were put into 7 age categories. The ELISA method was used to measure the anti-B19V IgG and the results showed the presence of antiB19V IgG in $70.09 \%$ of the females and $60.04 \%$ of the males (with a mean percentage of 65.63). In can be concluded from this study that females have a higher prevalence of $\mathrm{B} 19 \mathrm{~V}$ infection and the highest prevalence belongs to the pre-school aged children. (16)

\section{5-25 year-old people}

One study was conducted by Salimi et al in 2008 .

1500 blood samples were assessed in 2004 from Tehran, Iran.

1500 blood samples were Chosen from an original 5000 samples kept from the 2004 measles and rubella mass campaign in the Department of Virology in Tehran University of Medical sciences. Samples were studied for B19V IgG antibody and the results showed that $86.6 \%$ (1303) were positive for the B19V IgG antibody. The seropositive rates among males and females were $85.3 \%$ and $88 \%$ respectively $(\mathrm{P}=0.129)$. Also the aforementioned rates in rural and urban areas were $84.3 \%$ and $88 \%(\mathrm{P}=0.044)$. The antibody titer rises with increasing age significantly, starting from $79.3 \%$ in $5-9$ year-olds to $93.5 \%$ in 20 25 year-olds $(\mathrm{P}=0.000)(17)$.

\section{Parvovirus B19 in children with measles and rubella-like illness}

In this group only one study was conducted by Rezaei et al in 2016. 583 children aging from under 6 to 14 year-olds suffering from measles and rubellalike illness (exanthema) were involved in this survey.

IgM and $\operatorname{IgG}$ anti-bodies by ELISA and DNA by nested PCR were detected. 112 patients (19.21\%) were positive for B19V IgM antibody, 110 (18.87\%) were positive $\mathrm{B} 19 \mathrm{~V}$ IgG antibody, and 63 (10.81\%) were positive for B19V viral DNA. The rate of positivity for $\mathrm{B} 19 \mathrm{~V}$ IgG antibodies increased as the age increased, ranging between $7.11 \%$ in children under 6 years old, and $18.39 \%$ and $28.91 \%$ in $6-11$ year-olds and $11-14$ year-olds respectively. (18)

\section{Parvovirus in immunocompromised patients}

A total of three studies have been carried out on the HIV positive population.

The first study was conducted by Azadmanesh et al in 2015. 99 HIV positive patients plus 64 healthy controls were assessed.

Aiming to detect the prevalence and genotype of B19V among HIV-infected Iranians, this study examined 99 HIV-infected and 64 healthy(control) individuals for $\operatorname{IgG}$ and $\operatorname{IgM}$ antibodies against the virus and also the virus's DNA, using ELISA and nested PCR for antibodies and DNA respectively. The results demonstrated that the IgG, IgM, and DNA prevalence in the study group was $11.1 \%, 1 \%$, and $13.1 \%$, respectively. Also the same tests in the control group showed that the IgG, IgM, and DNA prevalence was $25 \%, 1.6 \%$ and $9.4 \%$, respectively. Every B19V isolate sequenced was the genotype $1 \mathrm{~A}$ and with little genetic diversity (19).

The second study was conducted by Aghakhani et al in 2016. 99 HIV positive patients plus 64 healthy controls in Tehran were assessed.

Like previous study was conducted by the same researchers in 2014, at the Iranian Research Center for HIV/AIDS in Tehran. The 99 HIV positive patients and 64 normal people as control were enrolled in this study. The purpose was to detect the $\mathrm{B} 19 \mathrm{~V}$ virus prevalence, using serology tests and PCR, the results revealed that out of 99 HIV positive patients and 64 controls, $13 \mathrm{HIV}$ cases were positive for B19V DNA.

These researchers' conducted another clinical study 1 year later, investigating B19V viremia, B19V-specific antibodies and reporting the hematological findings and the clinical outcome. The results demonstrated that the patients who were all undergoing the same HAART treatment had no viremia. And the B19V IgG seroconversion had occurred only in two, and IgM was not found in none of them. And after a 1-year follow-up no anemia cases were found in the cases (20).

The $3^{\text {rd }}$ study was conducted by Abdollahi et al in 2014 . 90 HIV positive patients plus 90 healthy controls in Tehran, with the mean age of 37.20 were assessed.

The study examined $90 \mathrm{HIV}$-positive individuals and 90 controls with matching age and sex for B19V IgG 
and IgM antibodies among other clinical and laboratory factors. The results revealed the B19V $\mathrm{IgG}$ antibody prevalence to be $81.1 \%$ among the HIV-positive subjects and $28.9 \%$ among the control subjects $(\mathrm{P}<0.001)$. None of the patients were positive for B19V IgM antibody.

When different regimens of antiretroviral therapy were considered as factors a significant difference in B19V IgG antibody positivity rates was found. (21)

\section{Parvovirus B19 in Women with history of abortion/miscarriage}

A total of seven articles were directed in relation to pregnancy and abortion.

The $1^{\text {st }}$ study was conducted by Shabani et al in 2015.

100 placental tissues were assessed, Markazi province. Patients were admitted from awide spectrum of socioeconomic level in Markazi province.

This cross sectional study measured the prevalence of B19V using real-time PCR in 100 placental tissues which were fixed by formalin and whose cause of death was unknown.

Results showed a $6 \%$ positivity for B19V among the study group. The gestational age of all positive cases was under 20 weeks averaging at 12.3 weeks with the mothers' ages averaging at 28 years. Three of the positive cases had a history of abortion and all of them were collected during spring. (22)

The $2^{\text {nd }}$ study was conducted by Rahbar et al in 2015 . 94 women with spontaneous abortions, between 18 and 45 years old and a mean age of 28.4 were assessed. 4 patients were employed and 90 were unemployed.

Results showed that, 14 (14.9\%) women were suspicious and 17 (18.1\%) women positive for parvovirus specific antibody. There was no significant difference between the women's occupation, age, abortion, gestational age and having a child under six years Old. In this study, pregnant women were divided into three groups or more, according to number of pregnancies. Although most of the positive antibodies were among those with more than three parities, the difference of these three groups was not significant. (6) In 50\% of cases, 10-14 days after the infection, symptoms like erythema infectiosum, mild fever, headache, and impatience may be seen $(14,23,24)$. Transition of virus from the mother to the fetus is estimated about $25 \%$. The maximum possibility of

was $21.8 \%$ in pregnancy loss (case) and $20.8 \%$ in term pregnancy (control). B19V IgM antibody was detected in $10.3 \%$ of case and $6.5 \%$ in control. There was no significant difference in $\operatorname{IgG}$ antibody virus transition is a week after the infection, when there is the maximum concentration of virus in mother's blood, and then $\operatorname{IgM}$ antibody starts appearing in circulation. By increasing gestational age, the incidence of infection and fetal death decreases. $(24,25)$

The $3^{\text {rd }}$ study was conducted by Khameneh et al in May and September 2011. Serum samples from 86 pregnant women were collected with the mean age of $25.56 \pm$ 5.30 years from west Azarbaijan province.

As result Anti-B19V-specific IgG antibody was detected in $(65 / 86,75.6 \%)$ of pregnant women. Three women had a documented history of blood transfusion ( 2 of them tested seropositive for B19V). 16/18(88.8\%) of all women who had a documented history of abortion tested positive for IgG. Frequency of abortion sessions in anti-B19V IgG positive women was 4.03 times more than the seronegative group. (26)

The $4^{\text {th }}$ study was conducted by Shahsiah et al in 2011 . 31 placental tissues and 31 control cases from Tehran, Iran were enrolled.

Thirty-one formalin fixed paraffin embedded placental tissue from autopsies related to fetal losses and also the same number of control cases were collected and the PCR for internal control and target sequence were performed. Three out of 31 cases were positive for parvovirus $(9.7 \%)$ using PCR. Hydropic changes were noted in two of positive cases for parvovirus. (27)

the $5^{\text {th }}$ study was conducted by Borna et al in 2009. 19 pregnancies from women aging between 18 and 45 years from 2007 to 2008 were enrolled. The mean gestational age was 27.7 weeks (range 21.2-33.4 weeks)

As a part of this study Maternal serologic analyses performed for parvovirus. The tests for CMV and B19V infection were made by PCR method. A total of two cases of diagnosed anemia in one case of $\mathrm{cmv}$ and another B19V were detected. In the case of B19V infection, ascites and edema were observed at 28 weeks of gestational age, and the MCA-PSV was greater than 1.5 MoM. Hemoglobin concentration was $6.5 \mathrm{~g} / \mathrm{dl}$ in this time. At 34 weeks, the hydrops had resolved, and a healthy baby was delivered at 36 weeks. (28)

the $6^{\text {th }}$ study was conducted by Keikha et al in 2006 . 168 women with term pregnancy (controls) and 156 women with pregnancy abortion at first and second trimester (cases) from 2001 to 2002 were enrolled in Zahedan.

To determine the seroprevalence of $\mathrm{B} 19 \mathrm{~V}$ infection in obstetric population, both virus specific anti- $\operatorname{IgG}$ and anti-IgM antibodies were assayed by ELISA method. B19V Anti-IgG positive rate

between the groups by the age and parity. But the prevalence of B19V IgM antibody was higher in women with unsuccessful pregnancy. (29) 
and the $7^{\text {th }}$ study was conducted by Ziyaeyan et al in 2005. 91 to-be-married girls, 184 pregnant women, and 184 neonates born to the second group women were enrolled in Shiraz, Iran.

Results showed that the prevalence of $\mathrm{IgG}$ for $\mathrm{B} 19 \mathrm{~V}$ was $56(61.5 \%), 127(69 \%)$, and $127(69 \%)$ for the first, second, and third groups, respectively. Overall, 183 out of the 275 (66.5\%) women of childbearing age had $\mathrm{IgG}$ for $\mathrm{B} 19 \mathrm{~V}$. The seroprevalence for $\operatorname{IgM}$ for B19V was $2.2 \%$ forth second group. (30)

\section{Parvovirus in transplant patients}

\section{Renal transplant patients}

Two studies conducted by Ardalan et al in 2008 concerned renal transplantation.

The $1^{\text {st }}$ study 6 renal transplant patients from a single center between January and March 2007 were enrolled in Tabriz, Iran.

Results showed that in 6 patients there was a temporal association between active B-19 infection and thrombotic microangiopathy and intrarenal small and medium-sized vessel vasculitis. (31)

the second study in April 2007, a 24-year-old male was assessed.

The presence of anti-B19V IgM antibody and viral DNA in the patient's serum detected by real-time PCR that confirmed an acute B19V infection. First report of B19V-associated HLH and thrombotic microangiopathy was in a 24-year-old male renal recipient, who presented with fever, severe anemia and allograft dysfunction after two years following transplantation. (32)

\section{Kidney transplant patients}

Other possible routes of transmission of B19V its donor graft, Renal transplant recipients are susceptible to viral infections because of their immunocompromised background (33-37).

Only one study was conducted in this group, by Khameneh et al in 2014. 91 transplant recipients were assessed in Urumia, Iran.

63 patients $(69.2 \%)$ were seropositive for B19V, 22 patients $(24.2 \%)$ were seronegative and six patients $(6.6 \%)$ had an $\mathrm{IgG}$ titer in the borderline range. The mean anti-B19V IgG titer in the seropositive group was $83.0 \pm 63.7$, and $2.38 \pm 1.51$ in the seronegative group $(\mathrm{P}=0.000)$. (38)

\section{Parvovirus B19 in Thallasemic patients}

One study was conducted by Nikoozad etal in 2015 in this group. 60 subjects comprising 30 thalassemia patients and 30 healthy individuals.

The Chi- square test showed a significant difference between the thalassemia and control groups. By PCR test the $\mathrm{B} 19 \mathrm{~V}$ infection rate in the thalassemia patients was $20 \%$ and None of the healthy subjects tested positive for B19V. (39)

\section{Parvovirus in patients suffering from less frequent diseases}

\section{Patients suffering from hereditary spherocytosis}

One study was conducted by Alavi et al in 2015 in this group. A 4-year-old girl, her brother, and their mother were assessed.

Results show hemolytic anemias mostly hereditary spherocytosis complicated by B19V aplastic crisis. All affected family members presented with progressive pallor and jaundice after a febrile illness and developed some degrees of transient pancytopenia, not only anemia, all simultaneously in the course of their disease. (40)

\section{Patients suffering from Bone marrow suppression}

In this group one study was conducted by Mohammadi et al in 2013. 27 patients were assessed, mean age of patients was 33 (range: 15-67) years.

Of 27 patients, $16(59 \%)$ were male.

Molecular test used for detecting of B19V DNA. B19V was found in $7(26 \%)$. Idiopathic thrombocytopenic purpura was documented in two of the studied patients. (41)

\section{Patients suffering from Behcet's disease}


In this group two studies were conducted by Habibagahi et al and Irschick et al in 2015 and 2011 respectively.

The $1^{\text {st }}$ study:

55 patients with symptoms of BD were compared with 42 healthy persons.

55 plasma samples from cases best matching the symptoms of Behcet's disease were tested for the B19V DNA using quantitative real-time PCR. Also to conform the results ELISA was used to check their seropositivity. The prevalence of B19V IgM and IgG between patients and controls was not different. No correlation was found between the presence of antiB19V antibodies and the clinical observations of Behchet's disease (42).

the second study:

40 patients with $\mathrm{BD}$ were enrolled.

Patients originating from different regions of Iran were tested by molecular/serological methods for B19V. No parvovirus DNA was found in the controls or study cases. And the findings couldn't associate Behchet's disease with B19V infection. (43)

\section{Parvovirus B19 in hemophilia patients}

In this group only one study was conducted by Shooshtari et al in 2005.

180 hemophilic cases and 400 healthy controls aging between 1-45 years were studied for B19V IgG antibody from Shiraz, Iran. The prevalence of B19V IgG among hemophilic cases was found to be $74 \%$ (133 positive cases) with the controls' being 56.5\% (226 positive cases, $\mathrm{P}<0.001$ ), there was a statistical significant difference between the two groups. (44) 


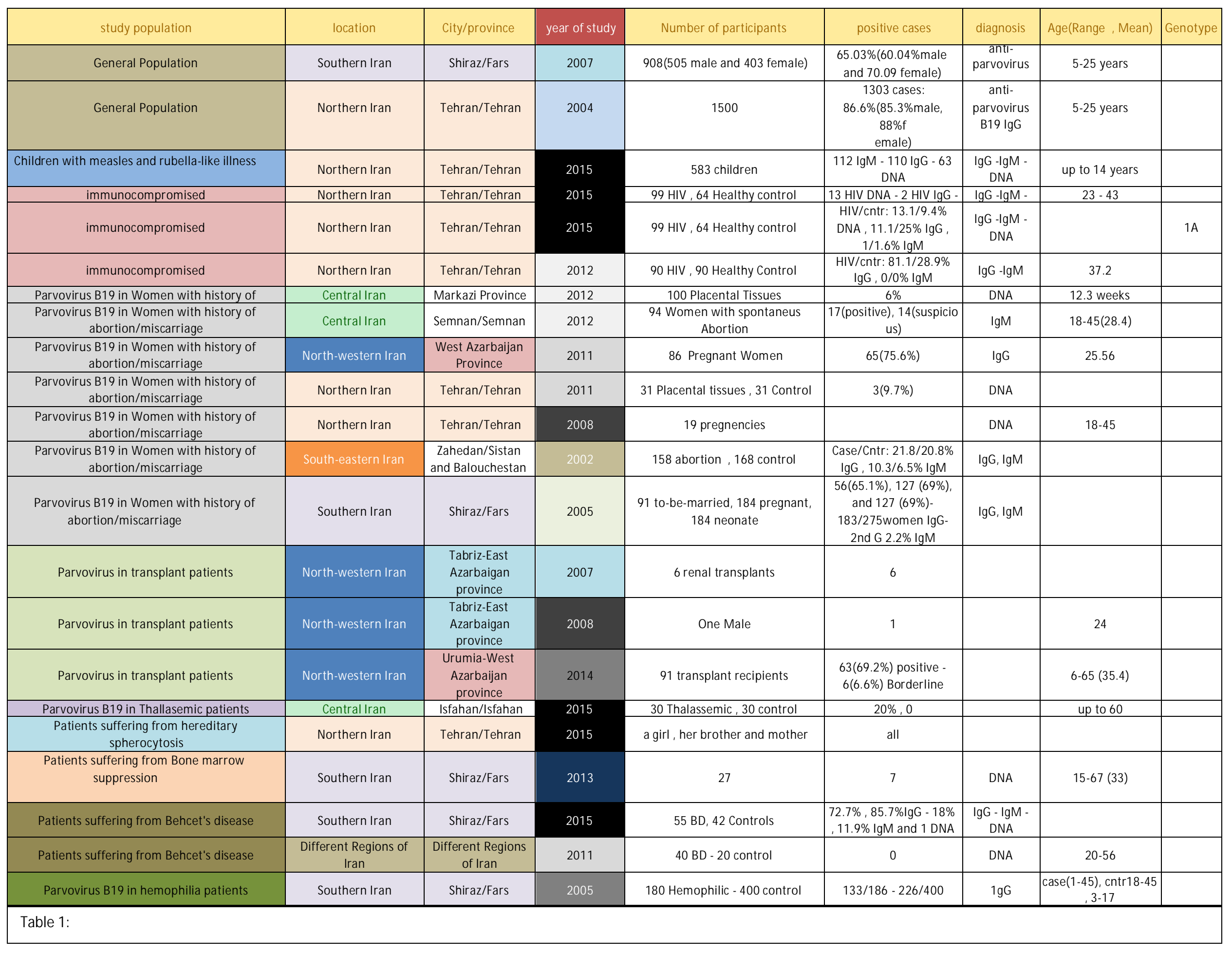




\section{Conclusion}

Parvovirus B19 still being the most pathogenic member of the family and it has been associated with a variety of diseases which results in a wide range of clinical presentations. Presence of rash/fever could be mistakenly reported as measles or rubella if laboratory testing is not performed. In this systematic review we outlined the epidemiology of B19V diseases which conducted in. The yearly peak prevalence of B19V infection happens in spring; in addition, larger epidemic s happens every 4 years. B19V is a potential risk for patients receiving blood products like hemophiliac, thallasemic and other patients. These observations demonstrate that $\mathrm{B} 19 \mathrm{~V}$ is frequently transmitted in blood products and inactivating methods do not prevent transmission.

result showed the prevalence of $\mathrm{B} 19 \mathrm{~V}$ was significant difference between the thalassemia and hemophilia cases against control groups, and also there was a temporal association between active B-19 infection and thrombotic microangiopathy and intrarenal small and medium-sized vessel vasculitis, but the findings couldn't associate Behchet's disease with B19V infection. In pregnancy women most of the positive antibodies were among those with more than three parities. In $50 \%$ of cases, 10-14 days after the infection, symptoms like erythema infectiosum, mild fever, headache, and impatience may be seen. By increasing gestational age, the incidence of infection and fetal death decreases. Frequency of abortion sessions in anti-B19V IgG positive women was 4.03 times more than the seronegative group.

Totally in blood recipients, that have any type of disease affects the immune system, it may seem important, therefore, B19V should be considered as an important way of developing the disease in these individuals.

\section{Acknowledgment}

We would like to thank Professor Maria Soderlund-Vevermo for her support and valuable comments. This study was funded by Vice-chancellor for Research and Technology, Hamadan University of Medical Sciences (No. 9604132250).
1. Ozawa K, Ayub J, Hao Y, Kurtzman G, Shimada T, Young N. Novel transcription map for the B19 (human) pathogenic parvovirus. Journal of virology. 1987;61(8):2395-406.

2. Srivastava A, Lu L. Replication of B19 parvovirus in highly enriched hematopoietic progenitor cells from normal human bone marrow. Journal of virology. 1988;62(8):3059- 63.

3. Brown K, Young N. Parvovirus B19 infection and hematopoiesis. Blood reviews. 1995;9(3):176-82.

4. Heegaard ED, Brown KE. Human parvovirus B19. Clinical microbiology reviews. 2002;15(3):485505.

5. Daly P, Corcoran A, Mahon BP, Doyle S. High-sensitivity PCR detection of parvovirus B19 in plasma. Journal of clinical microbiology. 2002 Jun 1;40(6):1958-62.

6. Norja P, Eis-Hübinger AM, SöderlundVenermo M, Hedman K, Simmonds P. Rapid sequence change and geographical spread of human parvovirus B19: comparison of B19 virus evolution in acute and persistent infections. Journal of virology. $2008 \mathrm{Jul}$ 1;82(13):6427-33.

7. Hino $\mathrm{M}$, Ishiko $\mathrm{O}$, Honda KI, Yamane $\mathrm{T}$, Ohta K, Takubo T, Tatsumi N. Transmission of symptomatic parvovirus B19 infection by fibrin sealant used during surgery. British journal of haematology. 2000 Jan 1;108(1):194-5.

8. Blümel J, Schmidt I, Effenberger W, Seitz H, Willkommen H, Brackmann HH, Löwer J, Eis-Hübinger AM. Parvovirus B19 transmission by heat-treated clotting factor concentrates. Transfusion. $2002 \mathrm{Nov}$ 1;42(11):1473-81.

9. Allain JP, Stramer SL, Carneiro-Proietti AB, Martins ML, Da Silva SL, Ribeiro M, Proietti FA, Reesink HW. Transfusion-transmitted infectious diseases. Biologicals. 2009 Apr 1;37(2):71-7.

10. Nayeri UA, Bahtiyar MO. Parvovirus B19 Infection During Pregnancy. InObstetric Imaging: Fetal Diagnosis and Care (Second Edition) 2018 (pp. 685688).

11. Crane J, Mundle W, Boucoiran I, Gagnon R, Bujold E, Basso M, Bos H, Brown R, Cooper S, Gouin K, McLeod NL. Parvovirus B19 infection in pregnancy. Journal of Obstetrics and Gynaecology Canada. 2014 Dec 31;36(12):1107-16.

12. Jordan JA, Butchko AR. Apoptotic activity in villous trophoblast cells during B19 infection correlates with clinical outcome: assessment by the caspaserelated M30 Cytodeath antibody. Placenta. 2002 Aug 1;23(7):547-53.

13. Wildig J, Cossart Y, Peshu N, Gicheru N, Tuju J, Williams TN, et al. Parvovirus B19 infection and severe anaemia in Kenyan children: a retrospective case control study. BMC infectious diseases. 2010;10(1):88.

\section{References}


14. Rahbar N, ValiZadeh S, Ghorbani R, Kheradmand P. Prevalence of parvovirus B19 specific antibody in pregnant women with spontaneous abortion. Acta medica Iranica. 2015;53(3):168-72.

15. Bosman A, Wallinga J, Kroes A. Fifth disease every four years: parvovirus B19. Infectieziekten Bulletin. 2002; 13:215-9.

16. Ziyaeyan M, Pourabbas B, Alborzi A, Mardaneh J. Prevalence of antibody to human parvovirus B19 in pre-school age/young adult individuals in Shiraz, Iran. Pakistan journal of biological sciences: PJBS. 2007;10(10):1763-5.

17. Salimi V, Gouya MM, Esteghamati AR, Safaie A, Heshmat R, Saadatmand Z, et al. Seroepidemiology of human parvovirus B19 in 525-year-old age people in Iran. Iran J Public Health. 2008;37(4):19-25.

18. Rezaei F, Sarshari B, Ghavami N, Meysami P, Shadab A, Salimi H, et al. Prevalence and genotypic characterization of Human Parvovirus B19 in children with measles- and rubella-like illness in Iran. Journal of medical virology. 2016;88(6):947-53.

19. Azadmanesh K, Mohraz M, Kazemimanesh M, Aghakhani A, Foroughi M, Banifazl M, et al. Frequency and genotype of human parvovirus B19 among Iranian patients infected with HIV. Journal of medical virology. 2015;87(7):1124-9.

20. Aghakhani A, Mohraz M, AzadmaneshK, Moayedi-Nia S, Kazemimanesh M, Mamishi S, et al. No evidence of persistent parvovirus B19 viremia among Iranian patients with HIV after a 1year follow-up. Archives of virology. 2016;161(5):1183-7.

21. Abdollahi A, Shoar S, Sheikhbahaei S, Mahdaviani B, Rasoulinejad M. Status of immunity against PVB19 in HIV-infected patients according to $\mathrm{CD} 4(+)$ cell count, and antiretroviral therapy regimen groups. Nigerian medical journal: journal of the Nigeria Medical Association. 2014;55(1):203.

22. Shabani Z, Esghaei M, Keyvani H, Shabani F, Sarmadi F, Mollaie H, et al. Relation between parvovirus B19 infection and fetal 
mortality and spontaneous abortion. Medical journal of the Islamic Republic of Iran. 2015; 29:197.

23. Nunoue T, Kusuhara K, Hara T. Human fetal infection with parvovirus B19: maternal infection time in gestation, viral persistence and fetal prognosis. The Pediatric infectious disease journal. 2002;21(12):1133-6.

24. de Haan TR, Oepkes D, Beersma MF, Walther FJ. Aetiology, diagnosis and treatment of hydrops foetalis. Current Pediatric Reviews. 2005;1(1):63-72.

25. Enders M, Weidner A, Zoellner I, Searle K, Enders G. Fetal morbidity and mortality after acute human parvovirus B19 infection in pregnancy: prospective evaluation of 1018 cases. Prenatal diagnosis. 2004;24(7):513-8.

26. Khameneh ZR, Hanifian H, Barzegari R, Sepehrvand N. Human parvovirus B19 in Iranian pregnant women: a serologic survey. Indian journal of pathology \& microbiology. 2014;57(3):442-4.

27. Shahsiah R, Monajemzadeh M, Hoseinzadeh H, Ashtiani MTH, Hantooshzadeh S, Alamooti AA, et al. Parvovirus B19 infection frequency in placenta of fetal loss cases in children medical center, Tehran, Iran. Iran J Pathol.2011;6(4):202-7.

28. Borna S, Mirzaie F, Hanthoush-Zadeh S, Khazardoost S, Rahimi-Sharbaf F. Middle cerebral artery peak systolic velocity and ductusvenosus velocity in the investigation of nonimmune hydrops. Journal of clinical ultrasound: JCU. 2009;37(7):3858.

29. Keikha F, Miri-Moghaddam E, SharifiMood B. Prevalence of parvovirus B19 infection in successful and unsuccessful pregnancy in Zahedan, southeast of Iran. J Med Sci (Pakistan). 2006;6(3):495-7.

30. Ziyaeyan M, Rasouli M, Alborzi A. The seroprevalence of parvovirus B19 infection among to-be-married girls, pregnant women, and their neonates in Shiraz, Iran. Japanese journal of infectious diseases. 2005;58(2):95-7.

31. Ardalan MR, Shoja MM, Tubbs RS, Jayne D. Parvovirus B19 microepidemic in renal transplant recipients with thrombotic microangiopathy and allograft vasculitis.
Experimental and clinical transplantation: official journal of the Middle East Society for Organ Transplantation. 2008;6(2):137-43.

32. Ardalan MR, Shoja MM, Tubbs RS, Esmaili H, Keyvani H. Postrenal transplant hemophagocytic lymphohistiocytosis and thrombotic microangiopathy associated with parvovirus b19 infection. American journal of transplantation: official journal of the American Society of Transplantation and the American Society of Transplant Surgeons. 2008;8(6):1340- 4.

33. Murer L, Zacchello G, Bianchi D, Dall'Amico R, Montini G, Andreetta B, et al. Thrombotic microangiopathy associated with parvovirus B 19 infection after renal transplantation. Journal of the American Society of Nephrology. 2000;11(6):1132-7.

34. Yango A, Morrissey P, Gohh R, Wahbeh

A. Donor-transmitted parvovirus infection in a kidney transplant recipient presenting as pancytopenia and allograft dysfunction. Transplant infectious disease. 2002;4(3):163-6.

35. Zolnourian ZR, Curran MD, Rima BK, Coyle PV, O'neill HJ, Middleton D. ParvovirusB19 in kidney transplant patients. Transplantation. 2000;69(10):2198-202.

36. Khameneh ZR, Sepehrvand N, Masudi S, Taghizade-Afshari A. Seroprevalence of HTLV-1 among kidney graft recipients: a single-center study. Experimental and clinical transplantation : official journal of the Middle East Society for Organ Transplantation. 2010;8(2):146-9.

37. Khameneh ZR, Sepehrvand N, TaghizadehAfshari A, Motazakker M, Ghafari A, Masudi S. Seroprevalence of herpes simplex virus-2 in kidney transplant recipients: a single- center experience. Iranian journal of kidney diseases. 2010;4(2):158.

38. Khameneh ZR, Sepehrvand N, SohrabiV, Ghasemzadeh N. The seroprevalence of Parvovirus B19 among kidney transplant recipients: a singlecenter study. Saudi journal of kidney diseases and transplantation: an official publication of the Saudi Center for Organ Transplantation, Saudi Arabia. 2014;25(1):16-21.

39. Nikoozad R, Mahzounieh MR, Ghorani MR. Detection of Parvovirus B19 Infection in 
Thalasemic Patients in Isfahan Province, Iran. Jundishapur journal of microbiology. 2015;8(11): e26590.

40. Alavi S, Arabi N, Yazdi MK, Arzanian MT, Zohrehbandian F. Hereditary spherocytosis unmasked by human parvovirus b19 induced aplastic crisis in a family. Iranian journal of medical sciences. 2015 Sep;40(5):461.

41. Mohammadi B, Yaghobi R, Dehghani M, BehzadBehbahani A. The molecular prevalence of viral infections in transplant candidates with bone marrow suppression, shiraz, southern Iran, 2010. International journal of organ transplantation medicine. 2013;4(2):87-94.

42. Habibagahi MP, Habibagahi ZM, Saidmardani SMM, Sadeghian FM. No Definite Association between Human Parvovirus B19 Infection and Behcet Disease. Iranian journal of medical sciences. 2015;40(6):493-500.

43. Irschick EU, Philipp S, Shahram F, Schirmer M, Sedigh M, Ziaee N, et al. Investigation of bacterial and viral agents and immune status in Behcet's disease patients from Iran. International journal of rheumatic diseases. 2011;14(3):298-310.

44. Shooshtari MM, Foroghi MN, Hamkar R. High prevalence of parvovirus B19 IgG antibody among hemophilia patients in center for special diseases, Shiraz, Iran. Iran J Public Health. 2005;34(1):51-4. 